\title{
INTEGRATION OF THE ICAO TRAINING INSTITUTE INTO THE INTERNATIONAL EDUCATION NETWORK
}

\author{
Mykola Kulyk, Galyna Suslova \\ National Aviation University, 1 Kosmonavta Komarova Ave., Kiev 01058. Ukraine \\ E-mail: eduicao@nau.edu.ua
}

Received 07 February 2012; accepted 15 May 2014

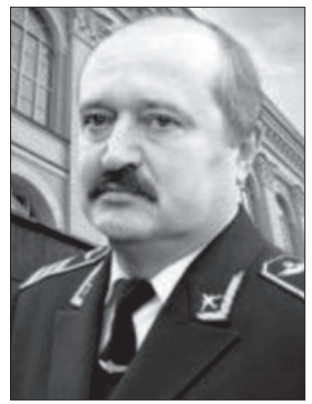

Mykola KULYK, Prof. Dr Sci. Eng.

Education: Kiev Institute of Civil Aviation Engineers, 1976. 1993 - Doctor of Science

(Engineering). 1994 - Professor.

Affiliations and functions: 1997 - head of the Department of Air Engines, 2008 - rector of the National Aviation University.

Honours, awards: an honoured person of science and engineering of Ukraine, winner of the State Prize of Ukraine in the area of science and technology.

Research interests: automatic systems of aircraft engine technical conditions.

Publications: over 200 scientific papers.

Present position: rector of the National Aviation University, Ukraine.

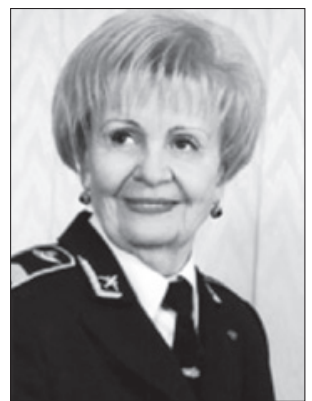

Galyna SUSLOVA, Prof.

Education: Gorkovskiy State University.

Affiliations and functions: an honoured person in Ukraine's education area, an honorary professor of Korea Aerospace University (South Korea) and Vilnus Gediminas Technical University (Lithuania), head of ICAO Training Institute, ICAO expert.

Research interests: safety management systems, aviation specialist training.

\begin{abstract}
Training plays a crucial role in ensuring the development and implementation of international Standards and Recommended Practices in aviation activities. Considering the existing policies and practices, the experts agreed on seven principles that the pan-European training policy should follow: promoting training, developing competency-based training, establishing an aviation culture, fostering mutual recognition, anticipating needs, supporting competition in training, ensuring quality of training and establishing a partnership with non-ECAC States. The ICAO Training Institute (National Aviation University, Kiev, Ukraine) fully meets the membership criteria of the European ECAC Network of Training Organisations and is accepted as a member of the network. The key activities include negotiations on cooperation, quality improvement and experience exchange, coordination of training programmes, development of new training programmes and training materials and creation of the pool of non-mandatory training courses.
\end{abstract}

Keywords: aviation specialist training, pan-European Network of Training Organisations, training policy, human resources, implementation of International Standards and Recommended Practices, safety thinking, human factor.

\section{Introduction}

The goal of aviation personnel training is to improve the safety and efficiency of air transport through the establishment and maintenance of high standards of training and competency for aviation personnel on a global basis
(ICAO... 2006b). The training institutions must meet an increasing demand for well-qualified personnel in a wide range of disciplines and emerging technologies. At the same time, the demands are greater than the resources available. 
The objectives of aviation personnel training are the following (ICAO... 2006a):

- to improve safety;

- to prevent accidents and serious incidents;

- to minimize the number of incidents and failures;

- to decrease the number of mistakes, violations and severity of their consequences;

- to reduce the influence of Human Factor;

- to develop a Safety culture;

- to harmonize knowledge and safety thinking on a global basis.

\section{European Training Policy}

Training plays a crucial role in ensuring the development and implementation of international Standards and Recommended Practices in aviation activities. European Civil Aviation Conference (ECAC) is committed to these aspects, and has undertaken many initiatives over the past years. Directors General of ECAC's 44 Member States endorsed an ECAC Training Policy defining the key principles to be promoted by ECAC and its Member States in terms of training in aviation and to guide ECAC activities in these areas. In this context, an ECAC network of training organisations is established with the following objectives:

- Encouraging cooperation between training organisations in Europe while respecting the role of each organisation in its specific areas of expertise;

- Improving the quality of training courses and programmes by proposing quality standards for the development, management and delivery of training courses and programmes;

- Facilitating the exchange of training experiences between training organisations, including the sharing of good practices in particular on conformity with set quality standards;

- Promoting "train the trainers" activities;

- Promoting the standardisation of training materials;

- Strengthening each other's capacity by reinforcing the training and expertise of their personnel.

The Directors General of ECAC Member States agreed that a High-Level Group on Training Policy should be established with the task to develop proposals for a training policy. The Membership of the Group ensured the participation of both policy makers and training experts. The Members of the Group included senior officials from Belgium, Bosnia and Herzegovina, France, Greece, Italy, Netherlands, Romania, Turkey, Ukraine and the United Kingdom.

Large States can play a more active role in safety and security training by having greater experience and more advanced resources, in particular human ones. Smaller States have limited internal resources for training and, therefore, have to recruit external consultants or send their staff abroad for training.

The range of available training programmes varied between countries and types of courses, i.e. mandatory and non-mandatory ones. In most cases the mandatory training programmes were considered to be sufficient but the situation with non-mandatory, yet still quite important, training courses was the opposite. The environment was considered to be one of the most demanded areas since a lack of training programmes was found in a majority of States.

Considering the existing policies and practices, the experts agreed on seven principles that should underpin the ECAC pan-European training policy. This policy should define the rules and principles to guide present and future decisions and include a high-level plan, embracing the organisation's general goals to achieve the desired outcome, reaching a high level of standards in safety and security both within and outside the ECAC region.

The ECAC Training Policy is based on the following principles (Ariduru 2011):

- Promoting training: despite the economic crisis, all Member States should continue to encourage and support a training organisation for their own staff and for staff of industry stakeholders (airport operators, ground handling agents, air carriers, cargo agents, etc.). The ECAC should promote education and training as a means to reach significant progress in terms of the delivery of satisfactory safety and security standards.

- Developing competency-based training: recognising the role of EASA in defining requirements for "regulated training" (e.g. positions requiring a licence such as pilot, etc.), ECAC efforts should focus on activities for which only minimum qualifications are defined and for which there are no specific training requirements, such as the economic and environment areas.

- Establishing an aviation culture: training can play an important role in establishing a common aviation culture in Europe. While recognising that there are differences between Member States on how the delivery of training is organised, the objective should be to ensure that a uniform level of training is achieved by the various entities developing and delivering training programmes.

- Fostering mutual recognition: establishing a common reference framework, including minimum qualifications, will enable Member States, training organisations, industry stakeholders and aviation professionals to compare qualifications across different training systems. This ability should facilitate the mutual recognition 
of competences and qualifications, and, subsequently, the mobility of people working in aviation within Europe.

- Anticipating needs: the European training system should be capable of anticipating new and emerging needs for training whether these needs come from new regulations, new technologies or new systems. The policy should promote anticipation of what training needs will be in the future and better communication on these needs with training providers. The forthcoming regulations will determine a series of new requirements on training, and will have an impact on needs for several categories of persons involved in aviation.

- Supporting competition in training: training is organised differently across ECAC Member States: ranging from a centralised system with a single training provider to an open market system, where the private sector develops and delivers training courses on the basis of the market demands. While in some countries there is a clear separation between the public and private sectors, public/private sector partnerships for some courses are conducted in other countries. The ECAC should support this market-based approach, while at the same time ensuring that training programmes are accessible at affordable costs, notably, by encouraging the availability of local/national/international training programmes, and also by promoting learning at the workplace, and by facilitating on-the-job training. Whether in the private or public sector, all training organisations should have equal opportunities to offer training programmes in the region.

- Ensuring quality of training: the quality of training should be promoted, and initiatives, such as the definition of minimum competences for instructors, should be encouraged. Standardisation of the minimum training content could contribute to the improvement of the quality and relevance of the training delivered. Training programmes should be developed by professional course developers, and also benefit from the experience of practitioners. Tools should also be developed to measure the effectiveness of training programmes.

- Establishing a partnership with non-ECAC States: Europe's training policy should include the promotion of European aviation culture internationally. Since our neighbouring states are interdependent, the European training system cannot live in isolation and should also consider the needs of these neighbouring States. Initiatives supporting and/or organising training courses could contribute to the development of air transport in other regions.

The scope and activities of the European Network shall fully comply with the principles defined in the Training Policy, particularly regarding fair and open competition between training organisations in the delivery of training courses as there is a free market for training in Europe and other regions of the world. The membership in the network shall not be used by the member organisations for commercial purposes or to share market opportunities. There are no time limitations for membership. As long as the training organisation continues to meet the membership criteria, it can remain a member of the network.

To satisfy the objective of improved quality of training, the membership in the network shall be open to any training organisation that meets the following objective membership criteria:

- a Government-recognised training organisation; or

- an ICAO-endorsed training organisation under the ICAO training policy;

- the training organisation has developed its own training materials, and has the ability to develop new training materials;

- a roster of course developers is available to the training organisation;

- a roster of trainers is available to the training organisation;

- it is not a purely commercial training organisation.

\section{The activities of the ICAO Training Institute at the National Aviation University (Kyiv, Ukraine)}

The ICAO Training Institute at the National Aviation University (Kiev, Ukraine) fully satisfies these requirements and is included into the European Network of Training Organisations. Since 2006 the ICAO Training Institute has trained about 6000 aviation specialists from more than 70 countries.

Among them there are CIS countries, Europe (Austria, Belgium, Bulgaria, the United Kingdom, Hungary, Greece, Spain, Italy, Switzerland, Finland, France, Croatia, Netherlands, Germany and others), the Asian region (Vietnam, China, India and others), African countries (Gambia, Sudan, Mauritania, Tunisia, South African Republic and others) and Middle East countries (Iran, Qatar, Oman, Bahrein, UAE and others).

Such a great variety of countries that are applying for training at the ICAO Training Institute demonstrate the attitude of the world aviation community towards this distinguished aviation training organization. The training is administered both in English and in Russian. 


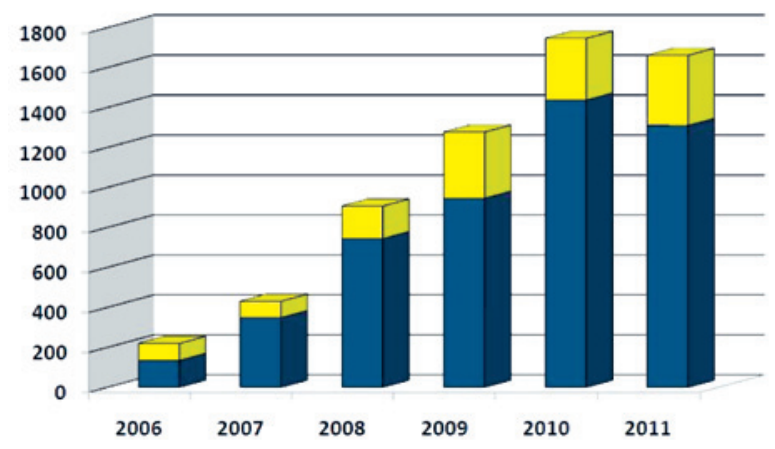

- Participants from Ukraine $\square$ Participants from foreign countries

Fig. 1 . The number of aviation specialists trained at the ICAO Training Institute since 2006

Highly skilled ICAO instructors: with basic aviation higher education (Master's degree), PhDs and Professors, experts from airlines and airports, and acting CAA inspectors certified by ICAO, are involved in the course delivery (Kulyk 2008). The ICAO Training Institute has obtained an ICAO endorsement to hold off-site training courses aimed at budget saving of aviation entities. The latter fact is of great importance nowadays because the aviation industry faces the problem of exponentially growing demand for well trained and qualified aviation professionals and the problem of strong competition from other industries for highly-skilled personnel (ICAO... 2011).

Having quite a significant experience in initial and recurrent training, the ICAO Training Institute has determined two problem areas peculiar for the majority of aviation entities: 1) the available staff is insufficiently trained and qualified; 2 ) there is an insufficient number of trained and qualified staff.

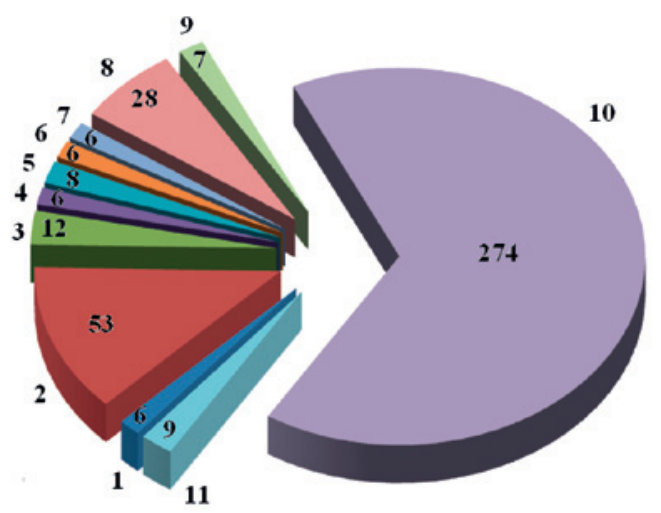

Fig. 2. The number of trainees who participated in the flight safety training courses at the ICAO Training Institute in 2011: 1 - Armenia, 2 - Azerbaijan, 3 - Belorussia, 4 - Congo, 5 - Georgia, 6 - Kazakhstan, 7 - Kyrgyzstan, 8 - Moldova, 9 - Tajikistan, 10 - Ukraine, 11 - others (Cameroon, Chad, Croatia, Lithuania, Oman, Russian Federation, Rwanda)

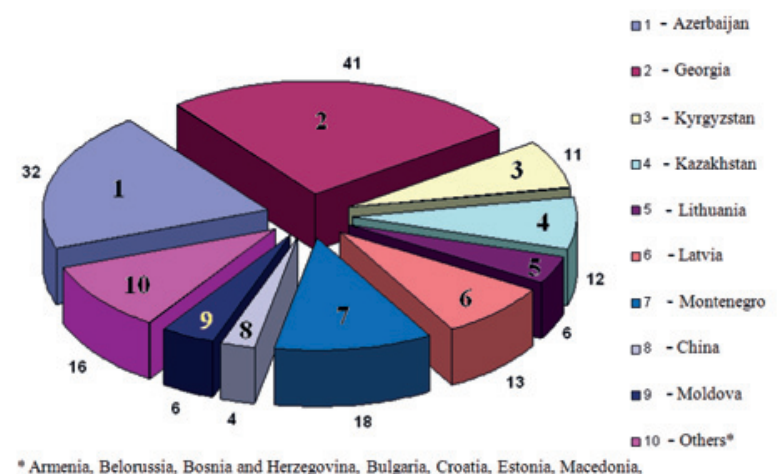
-Armenia, Belorussia, Bosnia and Herzegovina, Bulgaria, Croatia, Estonia, Macedonia,
Russia, Tajikistan, Uzbekistan

Fig. 3. The number of trainees who took part in the aviation security training courses at the ICAO Training Institute in 2011

The majority of States face challenges causing a lack of human resources:

- difficulty in attracting new staff (pilots, ATCOs, AMTs, aviation security personnel, etc.);

- poorly-motivated young aviation specialists;

- increasing and higher training requirements for a growing number of aviation activities and growing traffic (aviation safety and security);

- insufficient number of aviation training institutions;

- insufficient number of qualified instructors;

- insufficient training capacity in a broad range of disciplines;

- high training costs (including transportation costs, accommodation, per diems, etc.);

- brain drain;

- aging population of experienced aviation professionals;

- English language - as a barrier to non-English speaking countries;

- other barriers such as: economic and political differences, disparity of national regulatory systems, cultural differences, etc.;

- accountability to several stakeholders that may have priorities which are difficult to reconcile.

To cope with these challenges, first of all, it is necessary to take appropriate steps to improve the education system, the processes of initial and recurrent training, instructional techniques and resource management (ICAO... 2003). It is suggested that the improvement process should be commenced by taking into account the following organizational factors:

- implementation of Standards and Recommended Practices contained in Annex 1 to the Convention on International Civil Aviation;

- harmonization of national legislation with European and international legislation, in particular, harmonization of National training programmes; 
- establishment and certification of aviation training centres;

- training and certification of instructors on different subjects;

- promotion of safety assurance and inspection of the accountability and responsibilities of aviation entity management executives.

\section{Conclusions}

The integration of the ICAO Training Institute into the International education network is in progress. The key activities include negotiations on cooperation, quality improvement and experience exchange, coordination of training programmes, development of new training programmes and training materials (for example, training course on safeguarding civil aviation against cyber-threats, training courses on new European regulations, etc.) and development of the pool of non-mandatory training courses.

The overall objectives of the ECAC pan-European network of training organisations are implemented to provide added value, improve quality of training and exchange experience. The sharing of good practices among a large variety of training organisations and the development of higher quality standards represent the potential benefits of such a network.

\section{References}

Ariduru, A. 2011. DGCA/135-DP/8 Interim Report on ECAC Training Policy. Turkey.

ICAO Annex 1 to the Convention on International Civil Aviation. Personnel Licensing. 2006a.

ICAO Doc 7192: Training Manual. 2003. Part D-1. 2nd ed. Montréal, Québec: International Civil Aviation Organization. $147 \mathrm{p}$.

ICAO Doc 7300: Convention on International Civil Aviation. 2006b. 9th ed. $114 \mathrm{p}$.

ICAO Training Report. 2011. 1(1). July/August. Montréal, Québec: International Civil Aviation Organization (ICAO).

Kulyk, M. 2008. Continuous development is a guarantee of success, Aviation 12(3): 61-65.

http://dx.doi.org/10.3846/1648-7788.2008.12.61-65 